\title{
A distância transacional e a percepção de estudantes
}

Mauro Lorençatto. Faculdades Integradas Machado de Assis (FEMA).

Bolsista da CAPES - Proc. no 1432-11-7. maurolorencatto@ yahoo.com.br

Marie Jane Soares Carvalho. Universidade Federal do Rio Grande do Sul (UFRGS).

marie.jane@ufrgs.br

Resumo. Na Educação a Distância online é fundamental alterar o foco de discussão da distância geográfica e temporal para a distância psíquica e comunicacional. Nosso objetivo é contribuir para o desenvolvimento de arquiteturas pedagógicas apropriadas ao estabelecimento de proximidade comunicacional nos projetos de Educação a Distância online. A discussão mostra a relação entre as dimensões da distância transacional: estrutura, diálogo e autonomia do ponto de vista da percepção de acadêmicos que cursaram componentes curriculares optativos online. A base material desta percepção se encontra numa amostra de $25 \%$ da avaliação realizada pelos estudantes. Uma parte dos estudantes manifestou dificuldade em lidar com o AVA e considerou insuficiente a dinâmica deste para seus estudos. Uma porcentagem expressiva manifestou sentir solidão no dia-a-dia do componente curricular. A maioria dos estudantes percebe satisfatoriamente cada uma das dimensões, mas a percepção deles é insuficiente para sustentar o esclarecimento destas dimensões e de sua dinâmica institucional. $\mathrm{O}$ registro de suas percepções em avaliações institucionais contribui para que a instituição pense sobre si mesma, resguardando as limitações que se impõem.

Palavras-chave: educação a distância, distância transacional, percepção.

\section{The transactional distance and the perception of students}

Abstract. In online distance education is fundamentally altering the focus of discussion of the geographical distance and temporal distance to the psychological and communicational.

Our goal is to contribute to the development of appropriate teaching architectures to establish close communication in distance education projects online. The discussion shows the relationship between the dimensions of transactional distance, structure, dialogue and autonomy in terms of perceptions of academics who attended elective curriculum components online. The material basis of this perception is a sample of $25 \%$ of the evaluation made by students. One of the students expressed difficulty in dealing with the AVA and considered insufficient for the momentum of their studies. A significant percentage experience loneliness expressed in day-to-day component of the curriculum. Most students realize satisfactorily each of the dimensions, but their perception is insufficient to support the investigation of these dimensions and their institutional dynamics. The record of their perceptions of institutional evaluations contributes to think about the institution itself, bearing the constraints they impose.

Keywords: distance education, transactional distance, perception. 


\section{Introdução}

O desenvolvimento de novas Tecnologias Digitais, no decorrer das décadas de 1990 e 2000, conduziu à difusão das oportunidades, no que concerne à aprendizagem, através da combinação de recursos tecnológicos e humanos. A sua presença no sistema educacional faz com que seja necessário refletir sobre pontos intrínsecos à educação, como: didática, metodologia, planejamento, avaliação, plataformas e programas.

Os estudos sobre a Educação a Distância (EAD), em que o acadêmico não tem delimitação geográfica e nem sala de aula, têm crescido, pois a utilização das tecnologias digitais permitiu alargar o alcance e as possibilidades da EAD. As teorias sobre a Educação a Distância têm evoluído ao longo das últimas décadas, devido a pluralidade de atividades que se somam nesta modalidade. Dentre elas está a Teoria da Distância Transacional (Moore, 1997) que muda o foco de discussão da distância geográfica (espaço-tempo) para a distância psicológico-comunicacional entre professores e estudantes na modalidade EAD online.

Nosso foco é analisar os dados de uma avaliação solicitada a um grupo de estudantes sobre a utilização da Educação a Distância online, em quatro componentes curriculares optativos de cursos da área de Administração de uma instituição de ensino superior que atende a região de Santa Rosa - noroeste do estado do Rio Grande do Sul. Esta avaliação foi inicialmente pensada para contribuir no processo de seleção e uso dos recursos tecnológicos apropriados ao desenvolvimento da EAD na instituição. Ampliamos seu objetivo para pensar sobre o conceito de distância transacional proposto por Michael Moore no início da década de 1970, mas nomeado deste modo nos anos de 1990. A intenção é pensar a disposição dos componentes centrais da distância transacional a partir da percepção dos estudantes que participaram da primeira experiência nesta instituição. Os componentes da distância transacional em foco são: diálogo, estrutura e autonomia. Nosso questionamento se endereça para analisar a relação entre os componentes da distância transacional e seu efeito sobre a percepção dos estudantes em relação à recepção da EAD.

\section{Dicotomia entre presença e ausência}

A generalização do uso dos recursos da informática no cotidiano educacional promove outra fonte de informação (além das tradicionais: livros e professores), porque os novos meios de comunicação mudam as formas de interação entre as pessoas e o seu uso cotidiano influencia a metodologia de ensino-aprendizagem. A arquitetura da web 2.0 tem vocação para desenvolver a comunicação e interação e a EAD online, ancorada numa plataforma digital interativa e ou em ferramentas disponíveis na web, acumula demandas que se beneficia desta interação. Nosso foco é sobre componentes curriculares em EAD online que se desenvolveram em ambiente virtual de aprendizagem, como experimento numa instituição de ensino superior. E é a percepção dos estudantes sobre esta experiência que nos interessa mostrar.

A definição mais lembranda para a EAD tem como base a comparação com a modalidade presencial tradicional, tomando-a como referência. Este procedimento dificulta a percepção das particularidades da EAD como modalidade pedagógica, pois seu conjunto de características é considerado como um adorno à modalidade presencial. Assim pensada, as modalidades presencial e a distância são contrapostas entre si e contraditórias em si; como se a modalidade presencial e a modalidade a distância fossem excludentes e conflitantes entre si.

Todavia, não é o que diz a legislação brasileira. Como a educação a distância faz parte do contexto educacional, tem bases legais definidas. No Decreto n. ${ }^{\circ}$ 2.494, de 
10/02/1998, a EAD é definida assim "Art. $1^{\circ}$ - Educação a distância é uma forma de ensino que possibilita a auto-aprendizagem, com a mediação de recursos didáticos sistematicamente organizados, apresentados em diferentes suportes de informação, utilizados isoladamente ou combinados, e veiculados pelos diversos meios de comunicação" (Brasil, 1998).

O termo Educação a Distância não significa apenas ensino-aprendizagem pela web. A rede mundial de computadores interconectados é uma estrutura "a distância", porém, existem outras estruturas como o correio postal e mídias digitais offline. A definição do MEC (1998) abre a perspectiva de ver a EAD realizar-se tanto na forma mais antiga - a correspondência escrita - quanto por rádio e televisão e, mais recentemente, pela web, ou seja, com o suporte de computadores e pessoas interconectados.

Observa-se que o foco principal, nesses modos de realização da $E A D$, pressupõe a "autoaprendizagem", pois o estudante de educação a distância, na maior parte do tempo, encontra-se sozinho, o que não é sinônimo de estar isolado. O conceito também evidencia os "diversos meios de comunicação", contudo, neste trabalho, evidencia-se a EAD online, na qual os meios de comunicação são os recursos tecnológicos da web e, no caso considerado, usa-se uma plataforma digital, os programas de conversação e o correio eletrônico.

Sendo os meios de comunicação o fator diferenciado na aplicação da EAD, e tendo presente que o Paradigma Tecnológico da Informação (Castells, 2002) caracteriza a sociedade contemporânea pela sua fluidez na comunicação de informações para diversos propósitos, dentre eles, a Educação, entende-se a EAD online como uma modalidade educacional com características próprias, tais como Oliveira (2007, p. 34) apresenta:

a) "Extraterritorialidade" e a "temporalidade móvel", pois os sujeitos não compartilham, necessariamente, o mesmo espaço-tempo, embora possam fazê-lo em momentos prédeterminados;

b) Maior mediação tecnológica entre os sujeitos envolvidos, sem restrição de mídias comunicacionais, com uma tendência à predominância das tecnologias digitais pela facilidade e pela dinâmica

c) A intenção de desenvolver a autonomia do estudante, fazendo-o progredir do papel de "alvo do processo", que pressupõe o foco em uma ação externa a ele direcionada, para "centro do processo", como forma de construir a própria aprendizagem;

d) Uma intenção de dissolver as cisões e dicotomias entre "ensinantes" e "aprendentes", valorizando o caráter coletivo e colaborativo das ferramentas de comunicação disponíveis.

É no sentido de fortalecer a ideia de que a EAD online pode ser uma modalidade educacional autônoma e não apenas figurante da modalidade presencial que se apresenta a Teoria da Distância Transacional (Moore, 1991 e 1993). A teoria põe em evidência que a distância geográfica não é sinônimo de afastamento no processo de ensino-aprendizagem. A dinâmica de interação via meios digitais pode otimizar características de aprendizagem dos estudantes que potencializam a aprendizagem.

\section{A teoria da Distância Transacional}

Quando se fala ou se discute o termo "distância" a primeira lembrança é a que se refere ao "espaço físico" e ao "período temporal". Esta é uma visão legítima e se prolonga desde a Grécia até fim do século passado. E na perspectiva da educação, a proximidade ou a distância é entre professor e estudante.

Desde a Grécia antiga educação envolve proximidade física de docentes e discentes. A tendência para estabelecer dicotomias, reforçada pela hegemonia do modelo cartesiano-mecanicista que imperou do século XVIII a meados do século XX, quando ocorreu a universalização do acesso à escola, consagrou a proximidade física como requisito para a aprendizagem e, por outro lado, a distância como um déficit a 
ser superado (Guadagnin et al., 2003, p. 02).

De acordo com Peters (2001), as primeiras tentativas para estabelecer princípios didáticos específicos para a educação a distância privilegiaram a busca de meios para reduzir, amenizar ou até mesmo anular a distância física. Moore, com o intuito de diferenciar distância física de distância psicológica (comunicacional) desenvolveu a Teoria da Distância Transacional (1972). Esta foi a primeira tentativa - em língua inglesa - a estabelecer um marco teórica específico para EAD.

O conceito de transação, segundo Moore (1993, p. 02), tem origem em Dewey, e quer dizer "a interação entre o ambiente, os indivíduos e os padrões de comportamento numa dada situação". Essa transação supera a distância fisica e temporal e estabelece a distância psíquica e comunicacional.

\begin{abstract}
A transação [...] ocorre entre professores e estudantes num ambiente que possui como característica especial a separação entre estudantes e professores, que se traduz por uma distância "física" e mesmo "temporal". Esta separação conduz a padrões especiais de comportamento dos intervenientes, afetando profundamente tanto o ensino quanto a aprendizagem. Com a separação surge um espaço psicológico e comunicacional a ser transposto; um espaço de potenciais mal-entendidos entre as intervenções do instrutor e as do estudante, ou seja, surge um novo "espaço" pedagógico e psicológico, em que ocorre uma forma diferente de comunicação; uma nova "transação".
\end{abstract}

Entretanto, a distância transacional é variável e não absoluta, pois cada estudante na relação com o professor estabelece um padrão de comunicação que não é exatamente o mesmo para todos os estudantes. A distância transacional influencia os comportamentos, assim como a comunicação dos agentes envolvidos no processo conduz a padrões especiais de relacionamento, diferentes dos padrões existentes no ensino presencial. A compreensão da distância transacional num programa educacional deve levar em conta três variáveis: o diálogo educacional, a estrutura do programa e a autonomia do estudante.

\title{
O diálogo educacional
}

É a partir do diálogo e por ele que a estrutura do programa será avaliada e a autonomia do estudante se realizará para mais ou para menos. Na teoria de Moore, compreende-se por diálogo "toda interação positiva", mesmo reconhecendo que existe no processo de ensinoaprendizagem interação negativa.

Um diálogo é intencional, construtivo e valorizado por cada parte. Cada parte num diálogo é um ouvinte respeitoso e ativo; cada uma elabora e adiciona algo à contribuição de outra parte ou partes. Pode haver interações negativas ou neutras; o termo "diálogo" é reservado para interações positivas [...]. O diálogo em uma relação educacional é direcionado para o aperfeiçoamento da compreensão por parte do estudante (Moore, 1993, p. 03)

Um dos fatores mais importantes para a existência de diálogo na EAD é o meio de comunicação, contudo, não é meio de comunicação em si - por mais atrativo que seja - o responsável pela interação positiva entre professor e estudante. É através do diálogo que haverá dinamização e aprofundamento sobre o conteúdo estudado.

Dentre os fatores ambientais que influenciam o diálogo estão:

a) a natureza do meio de comunicação - o tipo de suporte midiático para o diálogo; quanto mais interativo, maior tende a ser a participação do estudante;

b) a personalidade do professor e do estudante - o professor pode decidir aproveitar pouco ou muito do potencial interativo do meio de comunicação do ambiente e o estudante pode escolher participar mais ou menos das propostas de interação do professor;

c) o conteúdo - dependendo da temática abordada ocorrem mais diálogos que em outras temáticas e mesmo em comparação à mesma área de estudo. Neste caso, envolve interesses pessoais e momento histórico. 
Quando o diálogo entre professor e estudante é ampliado, em qualquer situação, ocorre a redução da distância transacional, pois aproxima ambos, mesmo que estejam distantes geograficamente.

A estrutura do programa

A estrutura do programa é formada pelos elementos do projeto do curso e ou do componente curricular. A diferenciação de qualidade de um programa está expressa na medida em que ele pode responder a cada necessidade individual dos estudantes. Pensar um curso a partir do conceito de arquiteturas pedagógicas (Carvalho et al. 2007) permite que se antecipe caminhos curriculares possíveis, abertos e flexíveis. Este pressuposto é capaz de sustentar a construção mais autônoma dos estudantes. Cabe, então "pensar a aprendizagem como um trabalho artesanal, construído na vivência de experiências e na demanda de ação, interação e meta-reflexão do sujeito sobre os fatos, os objetos e o meio ambiente socioecológico" (Carvalho et al. 2007, p. 39). Para Moore a estrutura de um programa se abre a inúmeras possibilidades e se equilibra na relação entre os três componentes da distância transacional: diálogo, estrutura e autonomia.

Assim como o diálogo, a estrutura é uma variável qualitativa, e, tal como o diálogo, a extensão da estrutura num programa é normalmente determinada pela natureza dos meios de comunicação empregados, e também pela filosofia e características emocionais dos professores, pelas personalidades e outras características dos estudantes, e pelas restrições impostas pelas instituições educacionais (Moore, 1993, p. 05).

Quanto mais rígido for o programa, menor será a atenção personalizada ao estudante e, por consequência, a tendência é que seja maior a distância transacional. Por outro lado, se o programa for muito flexível poderá não alcançar o diálogo. Moore (1993, p. 6) afirma "o sucesso do ensino a distância depende da criação, por parte da instituição e do professor, de oportunidades adequadas para o diálogo entre professor e estudante, bem como de materiais didáticos adequadamente estruturados".

A produção de materiais didáticos adequados a cada conteúdo demanda o trabalho de uma equipe multidisciplinar e exige muito tempo, criatividade e reflexão na sua confecção. Entre os fatores que compõem a qualidade dos materiais didáticos está o conhecimento sobre o público-alvo, o contexto histórico, os modos de trabalho privilegiados do professor, o projeto pedagógico da instituição etc.

Em educação a distância o ensino raramente é um ato individual, mas sim um processo colaborativo que reúne em equipes de planejamento e redes de distribuição a competência de um certo número de especialistas. O modelo típico é o da equipe pedagógica composta por especialistas em conteúdo, designers instrucionais e especialistas em meios, equipe esta que fornece materiais estruturados que são usados como base para o diálogo entre estudantes, profes sores especializados e tutores (Moore, 1993, p. $6)$.

Todo programa em EAD deve ter sua estrutura para diminuir a distância transacional entre professor e estudantes. A teoria da distância transacional, de acordo com Moore (1993, p. 6-7) apresenta seis processos que devem ser pensados para diminuir a distância transacional:

a) Apresentação: exposição de informações, modelos, valores e habilidades através de textos, áudios, vídeos;

b) Apoio à motivação do estudante: o professor, através do diálogo, incentiva o estudante a aprender e a desenvolver automotivação para estudar o que é proposto e além;

c)

Estímulo à análise e à crítica: estas são habilidades cognitivas que estudantes de nível superior devem desenvolver para criar o senso de questionamento diante do que é tido como verdadeiro; 
d)

Aconselhamento e assistência: o programa educacional deve oferecer orientação sobre o uso do material didático, das técnicas para estudo e de algum tipo de referência para o enfrentamento de problemas pedagógicos;

e)

Organização de aplicação e avaliação: dar ao estudante a oportunidade de aplicar aquilo que aprende no intuito de concretizar seus conhecimentos e diante desta aplicação, o professor ou o tutor dá o feedback ao estudante;

Organização para a construção do conhecimento por parte do estudante: o programa deve provocar o estudante a esclarecer o seu processo de construção de conhecimento no intuito de ser uma reflexão sobre suas habilidades cognitivas de aprendizagem e condensação intelectual do próprio conhecimento.

Para oferecer programas de ensino eficazes na superação da distância física e temporal é preciso selecionar o meio apropriado para cada processo de ensino-aprendizagem, que tenha em conta as características do estudante, as do conteúdo, as do professor e a da instituição. A estrutura e sua dinâmica compõem a arquitetura pedagógica de uma disciplina ou curso, na qual se destaca um componente fundamental: a proposta pedagógica que incorpora a plataforma e os recursos digitais (Carvalho et al., 2007).

\section{A autonomia do estudante}

A autonomia do estudante na EAD é um fator determinante para o seu bom desempenho nas atividades. Ser autônomo não significa isolar-se na aprendizagem. A autonomia requer capacidade de escolha e confiança nas decisões do processo de aprendizagem. De um lado, a autonomia significa criar independência intelectual sem depender sistematicamente das intervenções de um professor. De outro, um programa de curso ou componente curricular pode criar ou não as condições para a construção da autonomia dos estudantes. Um programa fechado implica em menor autonomia do estudante. Entretanto, é necessário considerar que muitos estudantes não estão preparados para assumir o auto-direcionamento na aprendizagem em razão dos anos de treinamento escolar, nos quais eles não tiveram oportunidade de experimentar e desenvolver confiança na direção de sua aprendizagem. Por isso, nem sempre um curso flexível atende aos objetivos dos estudantes. Um curso flexível, que em tese permitiria alto grau de autonomia, pode levar ao fracasso uma parte considerável de estudantes que não se sente em condições de realizar e controlar a aprendizagem. $\mathrm{O}$ que aqui se espera dos professores, e de qualquer curso, é que eles possam ajudar os estudantes a construírem sua autonomia. Mesmo porque a autonomia não significa fazer as atividades ao seu bel-prazer. Ela implica numa lógica de relações entre os sujeitos em que a natureza dessa relação é a de parceria ao estabelecer uma base de diálogo que se estrutura na horizontalidade entre sujeitos que aprendem.

Não é fácil ser autônomo nos estudos de uma graduação se durante toda vida escolar o estudante foi treinado a ser dependente do professor para aprender. Mesmo os adultos têm dificuldades para serem autônomos, pois, na maioria dos casos, além de terem sido treinados para a dependência estão sem ritmo de estudo por terem se afastado durante 7, 10, 15 anos ou mais do hábito de estudar.

A autonomia pressupõe liberdade individual de escolha, porém, não significa excluir a coletividade da aprendizagem, pois é justamente a realidade das comunidades de aprendizagem um fator diferencial da modalidade EAD. O estudo pode e deve ser pensado na sua perspectiva de construção com o coletivo. Há inúmeras vantagens na colaboração recíproca e na amplitude da abrangência de experiências que podem ser compartilhadas. A cooperação no estudo não elimina do estudante a liberdade individual de construir seu caminho de aprendizagem que representa sua autonomia. Convém lembrar que "a autonomia está mais ligada a liberdade e autorregulação e estas características não são exclusivas do 
individuo e podem também ser exercidas em grupos, que podem surgir por indicação do professor ou também por iniciativa dos próprios participantes" (Guadagnin et al., 2003, p. 07).

A construção da autonomia no estudo é um desafio para a EAD. Ao mesmo tempo, não se pode pressupor que o único lugar de formação é na escola e para, além disso, pouco ou nada se fez. Isso quer dizer que os professores atuais, mesmo tendo sido formados na dependência de programas estruturados, desenvolveram competências por viver neste tempo - na sociedade da informação. Este tempo impôs condições muito diferentes de comunicação se comparadas com as condições de duas décadas atrás. E muitos professores investiram na apropriação destas condições, ainda que tenham limites de toda ordem a enfrentar.

É importante ter presente como os professores formadores se preparam para trabalhar em EAD, mas a apresentação de dados, neste trabalho, mostrará alcances e limitações da EAD da perspectiva dos estudantes, considerando a primeira investida de institucionalização desta modalidade numa instituição de ensino superior privada.

\section{A educação a distância na FEMA}

A Fundação Educacional Machado de Assis (FEMA), está localizada no município de Santa Rosa, região Noroeste do Estado do Rio Grande do Sul, com 68.587 habitantes (IBGE, 2010). Sua abrangência regional atende 20 municípios totalizando, aproximadamente, 230 mil habitantes. Esta região tem sua base econômica na agricultura (soja, milho e trigo), na indústria metal-mecânica (colheitadeiras) e na pecuária (leite). As faculdades têm acadêmicos de todas as cidades da microrregião. Como a maioria dos acadêmicos trabalha, os cursos são noturnos na modalidade presencial. A partir de 2010, com a criação do Setor de Projetos EAD, começou-se a planejar e sistematizar a implantação da modalidade a distância online e é sobre esta experiência que se propôs a avaliação aos estudantes.

\section{Implantação da modalidade EAD online}

No período de férias de verão de 2010-2011 foram ofertados aos acadêmicos do $4^{\circ}$ ao $8^{\circ}$ semestres, dos cursos de Ciências Contábeis e Administração componentes curriculares na modalidade a distância. Antes da oferta dos quatro componentes curriculares foram ministrados dois cursos de curta duração para todos docentes interessados na modalidade de educação a distância online.

No momento que as coordenações dos cursos aptos para ofertar vinte por cento (20\%) da grade curricular a distância (Brasil, 2004) decidiram quais seriam os componentes curriculares ofertados na modalidade a distância online foi ministrado um curso mais detalhado de formação docente para a utilização didática da plataforma Moodle.

A modalidade a distância online foi desenvolvida em quatro componentes curriculares (disciplinas) optativos: (1) Empreendedorismo e Criatividade Empresarial; (2) Sociologia; (3) Contabilidade de Pequenas e Médias Empresas e (4) Contabilidade Internacional.

Antes da finalização do segundo semestre de 2010, foram abertas as matrículas para a disciplina de Contabilidade Internacional. Os dois primeiros componentes iniciaram em dezembro de 2010 e outros dois em janeiro de 2011. O término das disciplinas foi em janeiro e fevereiro de 2011, antes do início do período letivo em fevereiro. A Tabela 1 mostra a situação dos estudantes por componente curricular.

Tabela 1 - Situação por Componente Curricular Optativo

\begin{tabular}{l|c|c|c|c}
\hline Componente Curricular Optativo & Matrículas & Evasão & Aprovação & Reprovação \\
\hline $\begin{array}{l}\text { Empreendedorismo e } \\
\text { Criatividade Empresarial }\end{array}$ & 75 & 00 & 72 & 03 \\
\hline Sociologia & 46 & 01 & 45 & 00 \\
\hline
\end{tabular}

V. $9 \mathrm{~N}^{\mathrm{o}}$ 2, dezembro, 2011 


\begin{tabular}{l|c|c|c|c}
\hline $\begin{array}{l}\text { Contabilidade de Pequenas e } \\
\text { Médias Empresas }\end{array}$ & 89 & 03 & 82 & 04 \\
\hline Contabilidade Internacional & 56 & 01 & 55 & 00 \\
\hline Total & 266 & 05 & 254 & 07 \\
\hline
\end{tabular}

O planejamento pedagógico de cada componente curricular, a distância online, construiu-se a partir de encontros entre o professor do componente e o coordenador de Projetos. Cada professor desenvolveu seu plano de ensino para 10 encontros e cada componente curricular teve um dia diferente da semana para facilitar a realização das atividades online, especialmente, para os acadêmicos que se inscreveram em dois componentes.

$\mathrm{Na}$ plataforma digital Moodle os professores utilizaram, com maior ou menos intensidade: fórum, chat, questionário, wiki (texto cooperativo), envio de Arquivo (produção acadêmica) e mensagens, além da biblioteca (textos, vídeos, materiais multimídia). Como parâmetro para a estrutura didática e o futuro melhoramento da modalidade, cada componente curricular online seguiu alguns critérios metodológicos, tais como: (1) do total de 10 aulas/atividades, 03 devem ser presenciais, sendo obrigatória a primeira aula (familiarização com o ambiente virtual: login, dinâmica e recursos) e a última. Dentre as oito restantes, mais uma aula presencial deveria ser incluíla. A sugestão é que as quinta e sexta aulas abordassem uma revisão e encaminhamentos; (2) dos 10 pontos que compõem o total da avaliação, três devem ser destinados à participação nas atividades online (fórum, questionários e wiki; (3) cada atividade proposta deve ter um feedback aos acadêmicos; (4) no dia da semana destinado à abertura e ao fechamento de atividades online, o professor deve permanecer online para sanar instantaneamente eventuais dúvidas dos acadêmicos; (5) além deste dia, é aconselhável que o professor acesse o ambiente virtual em outros dois dias semanais para dinamizar e focalizar o andamento das discussões propostas e; (6) cada componente curricular deve abrir no primeiro encontro (presencial) o fórum das dúvidas.

Estes encaminhamentos esclarecem parcialmente a estrutura da EAD na instituição e tem consequências na avaliação dos estudantes.

\section{A perspectiva dos estudantes}

Após a realização dos quatro componentes curriculares optativos, foi aplicado um questionário composto por 12 questões, das quais dez são objetivas e duas descritivas. $\mathrm{O}$ questionário foi disponibilizado por 14 dias no ambiente virtual. No total dos quatro componentes curriculares, 261 estudantes estavam aptos a realizar a avaliação. Deste total, 47 (18\%) responderam ao questionário. Entretanto, 71 acadêmicos se matricularam e participaram de dois componentes curriculares e, portanto, responderam somente uma vez a avaliação. Computando isso o percentual de respostas alcança $25 \%$ do total de estudantes.

Para análise do resultado serão apresentadas apenas as respostas das questões objetivas. A análise tem como referência as três dimensões da teoria da distância transacional: diálogo, estrutura e autonomia. As dez questões foram consideradas nas três dimensões, de acordo com o foco das questões.

As questões mais relacionadas com a dimensão do diálogo são: As atividades propostas pelo/a professor/a estavam claras e adequadas ao conteúdo? Como foi a interação com o professor/a? Como foi a interação com os colegas? Você sentiu solidão em relação a não-presencialidade corporal dos colegas e do professor/a no dia a dia do Componente Curricular? (Tabelas 2 e 3).

As questões mais diretamente relacionadas com a dimensão da estrutura em razão do foco no suporte das atividades desenvolvidas no ambiente virtual são: A dinâmica do 
Ambiente Virtual de Aprendizagem (AVA) ajuda no estudo? Você teve dificuldade para utilizar os recursos do AVA? Como foram elaboradas as atividades online (exercícios)? Como foram elaboradas as avaliações presenciais? (Tabela 4).

$\mathrm{E}$, por fim, as questões mais relacionadas à dimensão do esclarecimento da autonomia são: foco na realização pessoal - Você atingiu suas expectativas em relação a Educação a Distância no Componente Curricular? e foco na liberdade de escolha - Você cursaria outro Componente Curricular na modalidade a distância online na FEMA? (Tabelas 5 e 6).

Considerando que os níveis: "bom" e "ótimo" configuram uma avaliação positiva, e a soma destes varia entre $75 \%$ e $96 \%$, o resultado geral da perspectiva dos estudantes é positivo. Entretanto, uma questão chama atenção para seu alto índice do nível "regular". É a questão que trata da interação entre os colegas. Para as demais questões, o nível "regular" varia entre $2 \%$ e $10 \%$, à exceção da terceira pergunta na Tabela 2 que atinge o valor de $23 \%$ e requer atenção especial.

Tabela 2 - Distribuição da avaliação dos estudantes - dimensão do diálogo \%

\begin{tabular}{l|c|c|c|c|c}
\hline Questão/ Avaliação & Péssimo & Ruim & Regular & Bom & Ótimo \\
\hline $\begin{array}{l}\text { As atividades propostas pelo/a professor/a estavamclaras e } \\
\text { adequadas ao conteúdo? }\end{array}$ & - & - & 8,5 & 40.5 & 51,0 \\
\hline Como foi a interação com o profes sor/a? & - & 2,0 & 6,0 & 30,0 & 62,0 \\
\hline Como foi a interação com os colegas? & - & 2,0 & 23,0 & 43,0 & 32,0 \\
\hline
\end{tabular}

Fonte: Relatório de Avaliação EAD FEMA (Lorençatto, 2011).

Tabela 3 - Percepção da distância transacional - dimensão do diálogo \%

\begin{tabular}{|c|c|c|c|}
\hline Questão/ Avaliação & Sim & $\begin{array}{c}\text { As } \\
\text { vezes }\end{array}$ & Não \\
\hline $\begin{array}{l}\text { Você sentiu solidão em relação a não-presencialidade corporal dos colegas e do professor/a } \\
\text { no dia a dia do Componente Curricular? }\end{array}$ & 6,5 & 19,0 & 74,5 \\
\hline
\end{tabular}

Uma porcentagem expressiva de estudantes $(25,5 \%)$ manifestou sentir solidão no diaa-dia do componente curricular, sendo 6,5\% "sempre" e 19\% "às vezes" (Tabela 3), mesmo considerando que a maioria respondeu não se sentir só. Esta é uma das observações mais frequentes dos estudantes que realizam disciplinas ou cursos em EAD. Dentre as razões que esclarecem o fator solidão, encontram-se: (1) o projeto pedagógico não previu assistência suficiente capaz de fazer frente a esta situação; (2) a limitação de recursos financeiros impede a contratação de mais professores/tutores ou a ampliação da carga horária dos mesmos para fazer o atendimento necessário; (3) o estranhamento dos estudantes, a sua inexperiência com a modalidade a distância e, sobretudo, a sua imaturidade quanto ao trabalho autônomo são fatores que explicam a solidão. Vimos, anteriormente, que Moore (1993) chamou a atenção para o fato, já estudado também por outros autores, de que os estudantes recebem longo investimento escolar que não os habilita a ser mais independente.

Tão importante quanto ter presente os fatores acima é considerar que os professores da instituição estavam utilizando pela primeira vez o ambiente virtual de aprendizagem, portanto, eles não se encontravam suficientemente preparados para fazer um atendimento mais sólido aos estudantes. Considere-se, principalmente, que a primeira experiência na proposição de cursos ou disciplinas na modalidade a distância online exige maior investimento de tempo de todos os agentes educacionais até que se consolidem modos efetivos de atuar em EAD online. Isso também é parte do processo de uma instituição que investe em atividades na modalidade EAD online. A própria instituição aprende com a experiência e poderá responder mais adequadamente, no futuro, à distância transacional.

Tabela 4 - Distribuição da avaliação dos estudantes - dimensão da estrutura \% Questão/ Avaliação

\begin{tabular}{|l|l|l|l|l}
\hline Péssimo & Ruim & Regular & Bom & Ótimo \\
\hline
\end{tabular}

V. $9 \mathrm{~N}^{\mathrm{o}} 2$, dezembro, 2011 


\begin{tabular}{|c|c|c|c|c|c|}
\hline $\begin{array}{l}\text { A dinâmica do Ambiente Virtual de Aprendizagem (AVA) ajuda } \\
\text { no estudo? }\end{array}$ & - & - & 8,5 & 51,0 & 40,5 \\
\hline Você teve dificuldade para utilizar os recursos do AVA? & - & - & 10,0 & 38,0 & 52,0 \\
\hline Como foram elaboradas as atividades online (exercícios)? & - & 2,0 & 6,0 & 54,0 & 38,0 \\
\hline Como foram elaboradas as avaliações presenciais? & & 2,0 & 2,0 & 58,0 & 38,0 \\
\hline
\end{tabular}

Fonte: Relatório de Avaliação EAD FEMA (Lorençatto, 2011).

Ainda que a maioria dos estudantes avalie positivamente a estrutura (Tabela 4), convém ter presente que os estudantes não têm condições suficientes para fazer tal avaliação. Se Moore (1993) está correto sobre o fato de que os estudantes recebem mais treinamento na escola para responder aos professores e à estrutura do que investimento na sua autonomia, então, é de se esperar que eles não disponham de parâmetros que os habilite a proceder a este tipo de avaliação. Sua percepção, neste caso, é na melhor das hipóteses, uma vaga sensação de bem estar, insuficiente para pensar sobre as atividades e a avaliação propostas a eles.

O fato de $10 \%$ de estudantes terem manifestado dificuldade em lidar com o AVA e outros $8,5 \%$ que consideram insuficiente a dinâmica do AVA para seus estudos nos faz supor: a) o AVA não é tão intuitivo como poderia ser; b) os estudantes não se apropriaram do AVA; c) o AVA tem limitações e por isso uma porcentagem dos estudantes registra que este não fez diferença nem os ajudou nos estudos; d) o AVA, por si só, é insuficiente se se deseja que ele seja muito mais que um repositório de atividades. Neste caso, o projeto de uso do AVA exigirá integração substantiva com a pedagogia proposta pelo professor, tanto quanto exigirá maior investimento de tempo dos professores no acompanhamento e interação com os estudantes e, mais, exigirá investimento no aperfeiçoamento da sua arquitetura.

Tabela 5 - Distribuição da avaliação dos estudantes - dimensão da autonomia \% A

\begin{tabular}{l|c|c|c|c|c}
\hline Questão/ Avaliação & Péssimo & Ruim & Regular & Bom & Ótimo \\
\hline $\begin{array}{l}\text { Você atingiu suas expectativas em relação ao Ensino a Distância } \\
\text { no Componente Curricular? }\end{array}$ & - & - & 8,5 & 51,0 & 40,5 \\
\hline Fonte: Relatório de Avaliação EAD FEMA (Lorençatto, 2011).
\end{tabular}

Tabela 6 - Distribuição da avaliação dos estudantes - dimensão da autonomia \% B

\begin{tabular}{|c|c|c|}
\hline Questão/ Avaliação & Não & Sim \\
\hline Você cursaria outro Componente Curricular na modalidade a distância na FEMA? & 4,0 & 96,0 \\
\hline
\end{tabular}

Não se sabe quais são as expectativas dos estudantes, mesmo que a maioria das respostas tenha se situado entre bom e ótimo (Tabela 5). $\mathrm{O}$ mesmo podemos ponderar quanto a cursar outro componente curricular na modalidade a distância online. Não sabemos o que os motiva, mas podemos inferir que a experiência, ainda que breve, foi suficiente para que eles sejam receptivos à modalidade EAD (Tabela 6). E esta expectativa abre espaço institucional para qualificar os processos em EAD, as ferramentas digitais, a arquitetura do ambiente virtual de aprendizagem e os projetos pedagógicos que se endereçam a esta modalidade.

A correlação entre diálogo, estrutura e autonomia não pode ser estabelecida com base tão somente na percepção dos estudantes sobre alguns elementos da avaliação. $\mathrm{O}$ que se pode mostrar é que há convergência entre as três dimensões quando tratamos da percepção dos estudantes. A maioria percebe satisfatoriamente cada uma das dimensões, mas a percepção dos estudantes é insuficiente para sustentar o esclarecimento destas dimensões e de sua dinâmica institucional. Os estudantes, em razão de sua inexpressiva experiência com atividades que exigem autonomia durante sua formação escolar, quando chegam ao ensino superior, não dispõem de condições suficientes para avaliar o que acontece na instituição ou nos componentes curriculares. Todavia, sua manifestação em avaliações como esta ajuda a instituição a pensar sobre si, resguardando as limitações que se impõem. 


\section{Conclusão}

A Educação a Distância online é uma modalidade com características especificas de ensino-aprendizagem. Através dela se busca ampliar o acesso ao conhecimento, desde que a produção de conhecimento científico seja oriunda da reflexão sobre o conteúdo que o diálogo proporciona e não apenas o derramamento de informações ou a transferência dos modos do presencial na estrutura do ambiente de ensino-aprendizagem a distância.

A Distância Transacional é um conceito importante na EAD e para que se possam oferecer, nesta modalidade, cursos com qualidade é necessário buscar o equilibrio entre as dimensões que envolvem o diálogo, a estrutura e a autonomia dos estudantes. Esta visão deve ser levada em consideração no planejamento e desenvolvimento de componentes curriculares e ou cursos a distância online.

A maioria dos estudantes percebe satisfatoriamente cada uma das dimensões, mas a percepção dos estudantes é insuficiente para sustentar o esclarecimento destas dimensões e de sua dinâmica institucional. Os estudantes não dispõem de condições suficientes para avaliar o que acontece na instituição ou nas disciplinas em razão de sua inexpressiva experiência durante sua formação escolar com atividades que exigem autonomia. $\mathrm{O}$ fato de uma parte dos estudantes manifestarem dificuldade em lidar com o AVA e considerarem insuficiente a dinâmica do AVA para seus estudos nos leva a considerar que o ambiente virtual necessita de uma arquitetura mais amigável e condizente com os interesses e necessidades deles.

Uma porcentagem expressiva de estudantes manifestou sentir solidão no dia-a-dia do componente curricular.Esta é uma das observações mais frequentes dos estudantes que realizam disciplinas ou cursos em EAD. Dentre as razões que esclarecem o fator solidão, encontram-se: (1) o projeto pedagógico não previu assistência suficiente capaz de fazer frente a esta situação; (2) a limitação de recursos financeiros para investir em recursos humanos necessários ao bom desenvolvimento do curso; (3) o estranhamento e inexperiência dos estudantes com a modalidade a distância e, sobretudo, a sua imaturidade quanto ao trabalho autônomo.

O registro das percepções dos estudantes em avaliações institucionais contribui para que a instituição pense sobre si mesma, resguardando as limitações que se impõem.

\section{Referências}

BRASIL. Ministério da Educação. Decreto n. ${ }^{\circ}$ 2.494, de 10 de fevereiro de 1998. Disponível em: <portal.mec.gov.br/sesu/arquivos/pdf/dec_2494.pdf>. Acesso em: 23 set. 2011.

Portaria $\mathrm{n}^{\circ} 4.059$, de 10 de dezembro de 2004. Disponível em:

<http://portal.mec.gov.br/sesu/arquivos/pdf/nova/acs_portaria4059.pdf>. Acesso em: 23 set. 2011.

CARVALHO, Marie Jane S.; NEVADO, Rosane A.; MENEZES, Crediné S. Arquiteturas

pedagógicas para educação a distância. In NEVADO, Rosane A.; CARVALHO, Marie Jane S.; MENEZES, Crediné S. Apre ndizagem em rede na educação a distância: estudos e recursos para formação de professores. Porto Alegre: Ricardo Lenz, 2007, p. 35-52

CASTELLS, Manuel. A sociedade em rede. 6.ed. São Paulo: Editora paz e Terra, 2002.

GUADAGNIN, Luís Alberto; DUTRA, Renato L. de Souza; TAROUCO, Liane M. R. Seleção e uso de recursos instrucionais aptos ao estabelecimento de distância transacional adequada em cursos a distância. Revista Novas Tecnologias na Educação (CINTED-UFRGS), v. 01, n. 02, p. 20-29, set. 2003.

LORENÇATTO, Mauro. Avaliação Docente e Discente dos Componentes Curriculares Optativos de Verão 2010-2011. Santa Rosa-RS: FEMA, 2011. Relatório. 
MOORE, Michael. Distance Education Theory. The American Journal of Distance Education, v.3, n. 3, 1991.

Theory of transactional distance. In Keegan, D., (ed.). The oretical Principles of Distance Education. London: Routledge, 1997.

OLIVEIRA, Sheila da C. A Interlocução na Graduação a distância: Processo, Ferramenta e Resultado em Transição Paradigmática. Porto Alegre: UFRGS, 2007. Tese (Doutorado em Informática e Educação), Programa de Pós-Graduação em Informática e Educação, Universidade Federal do Rio Grande do Sul, 2007.

PETERS, Otto. Didática do ensino a distância. São Leopoldo: UNISINOS, 2001. 